\section{Original Article}

Check for updates

\title{
Prognostic Value of Skeletal Muscle Depletion Measured on Computed Tomography for Overall Survival in Patients with Non-Metastatic Breast Cancer
}

\section{OPEN ACCESS}

Received: Oct 4, 2019

Accepted: Dec 23, 2019

Correspondence to

Tae Hee Kim

Department of Radiology, Ajou University

School of Medicine, 164 World cup-ro,

Yeongtong-gu, Suwon 16499, Korea.

E-mail: h219435@gmail.com

c) 2020 Korean Breast Cancer Society

This is an Open Access article distributed under the terms of the Creative Commons Attribution Non-Commercial License (https:// creativecommons.org/licenses/by-nc/4.0/) which permits unrestricted non-commercial use, distribution, and reproduction in any medium, provided the original work is properly cited.

ORCID iDs

Jimi Huh (DD

https://orcid.org/0000-0002-8832-6165 Bumhee Park (iD)

https://orcid.org/0000-0002-5271-1571 Heirim Lee (iD)

https://orcid.org/0000-0002-8518-8983 Young-Sil An (D)

https://orcid.org/0000-0003-0777-6226 Yongsik Jung (iD

https://orcid.org/0000-0002-2011-1459 Ji Young Kim (iD)

https://orcid.org/0000-0001-5539-7269 Doo Kyoung Kang (iD)

https://orcid.org/0000-0002-5397-9334 Kyung Won Kim (D)

https://orcid.org/0000-0002-1532-5970

Tae Hee Kim (D)

https://orcid.org/0000-0002-0520-2395
Jimi Huh (1) ', Bumhee Park $\mathbb{1}^{2}$, Heirim Lee $\mathbb{C}^{2}$, Young-Sil An $\mathbb{1}^{3}$, Yongsik Jung (1) ${ }^{4}$, Ji Young Kim (10) ${ }^{4}$, Doo Kyoung Kang (1) ${ }^{1}$, Kyung Won Kim (1) ${ }^{5}$, Tae Hee Kim (1)

'Department of Radiology, Ajou University School of Medicine, Suwon, Korea

${ }^{2}$ Department of Biomedical Informatics, Ajou University School of Medicine, Suwon, Korea

${ }^{3}$ Department of Nuclear Medicine and Molecular Imaging, Ajou University School of Medicine, Suwon, Korea

${ }^{4}$ Department of Surgery, Ajou University School of Medicine, Suwon, Korea

${ }^{5}$ Department of Radiology, University of Ulsan, College of Medicine, Asan Medical Center, Suwon, Korea

\section{ABSTRACT}

Purpose: The purpose of this study was to evaluate the prognostic value of skeletal muscle depletion measured on computed tomography (CT) in patients with non-metastatic invasive breast cancer.

Methods: This retrospective study included 577 consecutive women (mean age \pm standard deviation: $48.9 \pm 10.2$ years with breast cancer who underwent a preoperative positronemission tomography (PET)/CT scan and curative surgery between January 2012 and August 2014. The total abdominal muscle area (TAMA), subcutaneous fat area (SFA), and visceral fat area (VFA) were measured on CT images at the L3 vertebral level. Univariate and multivariate Cox proportional-hazard regression analyses were performed to evaluate whether there was an association between sarcopenia and overall survival (OS) outcome.

Results: Of the 577 women, 49 (8.5\%) died after a mean of 46 months. The best TAMA threshold for predicting OS was $83.7 \mathrm{~cm}^{2}$. The multivariate Cox proportional-hazard analysis revealed that sarcopenia (TAMA $\leq 83.70 \mathrm{~cm}^{2}$ ) was a strong prognostic biomarker (hazard ratio [HR], 1.951; 95\% confidence interval [CI], 1.061-3.586), along with large tumor size, axillary lymph node metastasis, high nuclear grade, estrogen receptor status, and adjuvant radiation therapy. In the subgroup analysis of patients aged $\geq 50$ years, TAMA $\left(\leq 77.14 \mathrm{~cm}^{2}\right)$ was a significant independent factor (HR, 2.856; 95\% CI, 1.218-6.695).

Conclusion: Skeletal muscle depletion measured on CT was associated with worse OS outcome in patients with non-metastatic breast cancer.

Keywords: Breast; Carcinoma; Sarcopenia; Survival 


\section{Funding}

This work was supported by the National Research Foundation of Korea (No. 2019R111A1A01060744) and Central Medical Service.

\section{Conflict of Interest}

The authors declare that they have no competing interests.

\section{Author Contributions}

Conceptualization: An YS, Jung Y, Kim JY, Kang DK, Kim TH; Data curation: Park B, Lee H, An YS, Jung Y, Kim JY, Kim TH; Formal analysis: Park B, Lee H, Kim KW, Kim TH; Funding acquisition: Kim KW, Kim TH; Investigation: Huh J, Jung Y, Kim JY, Kang DK, Kim KW, Kim TH; Methodology: Huh J, Park B, Lee H, Kim KW; Project administration: An YS; Software: Kim KW; Supervision: Jung Y, Kang DK, Kim TH; Validation: Kim KW; Writing - original draft: Huh J, Kim TH; Writing - review \& editing: Kim TH.

\section{INTRODUCTION}

Improvement in early diagnosis and treatment has led to improved survival in breast cancer patients, such that the death rate decreased 39\% during the period 1989-2015 [1]. Many studies have reported decreasing mortality in breast cancer patients due to widespread use of adjuvant systemic therapy, endocrine therapy, and targeted therapy [2-4]. Five-year relative survival rates for non-metastatic breast cancer have been reported as $91 \%$ in Asian women and $86 \%$ in white women [5]. There are many well-known prognostic factors in breast cancer including younger or older age at the time of initial diagnosis, larger tumor size, advanced nodal stage, absence of hormone receptors, and overexpression of human epidermal growth factor receptor-2 (HER2) [6-10].

Sarcopenia is a disease characterized by reduced skeletal muscle mass and strength/function, which may decrease the quality of life while also increasing physical disability and mortality [11]. Recently, sarcopenia has gained attention as a prognostic factor of mortality in both non-metastatic and metastatic breast cancer [12-16]. In the meta-analysis by Aleixo et al. [17], breast cancer patients with a lower skeletal muscle index had a $68 \%$ greater mortality risk compared to patients with a higher skeletal muscle index. Many studies have demonstrated a relationship of sarcopenia with overall survival (OS) in patients with various types of cancer including lung cancer, stomach cancer, pancreatic cancer, and lymphoma [18-21].

The amount of skeletal muscle can be measured by a variety of techniques such as dualenergy X-ray absorptiometry, bioelectrical impedance analysis, and cross-sectional imaging including computed tomography (CT) or magnetic resonance imaging (MRI) [11]. In cancer patients, sarcopenia is generally assessed by measurement of the skeletal muscle mass on clinically acquired CT scans. In breast cancer patients, CT or positron-emission tomography (PET)/CT scans of the chest and abdomen are commonly acquired. Before skeletal muscle mass on CT can be used as a prognostic biomarker, abundant evidence of its utility from different breast cancer populations and clinical settings is needed. Currently, there is sparse evidence with respect to the prognostic value of skeletal muscle mass measured on CT in patients with non-metastatic breast cancer. Therefore, we aimed to evaluate the prognostic value of skeletal muscle mass measured on $\mathrm{CT}$ in this patient population.

\section{METHODS}

Our Institutional Review Board approved this retrospective observational study (AJIRB-MEDMDB-18-292), which waived the requirement for informed consent. This study is reported in accordance with the Transparent Reporting of a multivariable prediction model for Individual Prognosis or Diagnosis (TRIPOD) guidelines [22].

\section{Study population}

Between January 2012 and August 2014, we identified 648 consecutive women with newly diagnosed invasive breast cancer who had undergone both preoperative ${ }^{18} \mathrm{~F}$-labeled fluoro-2deoxyglucose $\left({ }^{18} \mathrm{~F}-\mathrm{FDG}\right) \mathrm{PET} / \mathrm{CT}$ imaging and subsequent breast surgery. We excluded 14 patients who had distant metastasis at presentation, 9 patients who had a previous breast cancer history, 11 patients who had bilateral breast cancer, 18 patients who had malignancy in other organs, and 19 patients who underwent vacuum-assisted breast biopsy in private clinics before MRI. Finally, 577 women (mean age, 48.9 years; age range: $26-81$ years) were included in this study (Figure 1). 


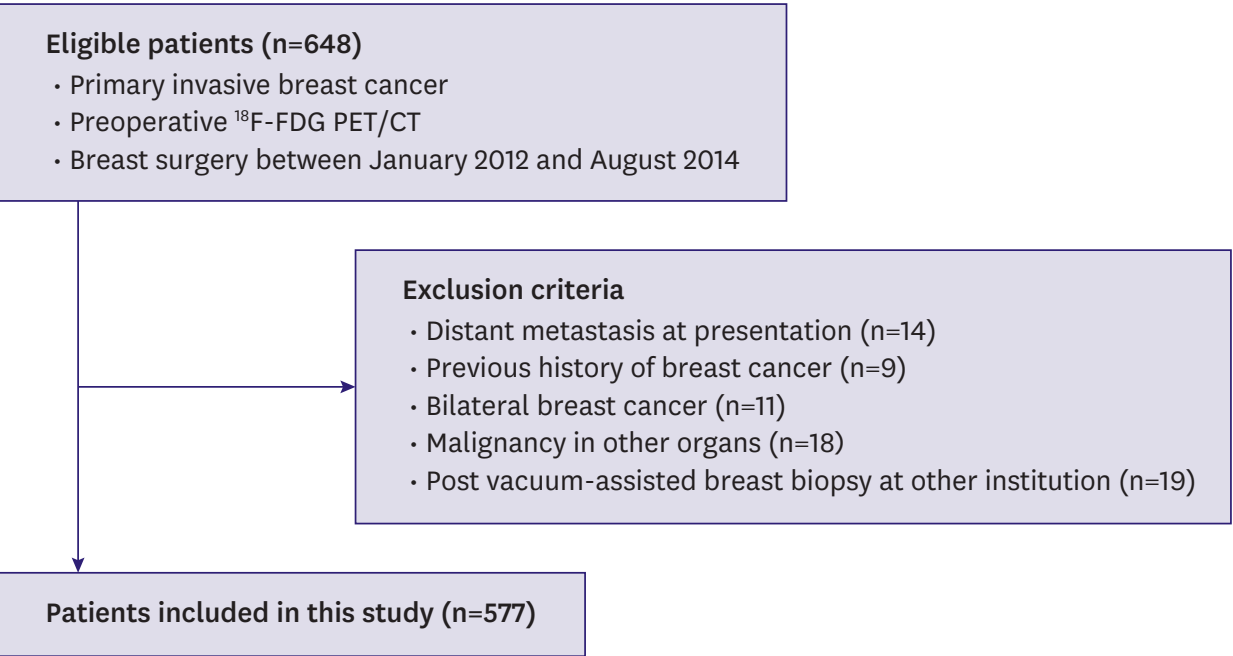

Figure 1. Flowchart of study population.

${ }^{18} \mathrm{~F}-\mathrm{FDG}={ }^{18} \mathrm{~F}$-labeled fluoro-2-deoxyglucose; $\mathrm{PET}=$ positron-emission tomography; $\mathrm{CT}$ = computed tomography.

\section{Clinicopathologic data collection}

Patients' clinical and pathological data were obtained from the medical records held by our hospital. Their demographic information, including age, sex, weight, height, and body mass index (BMI) was recorded. In addition, treatment-related information was obtained, such as the use of neoadjuvant/adjuvant chemotherapy; the follow-up period and OS data were also obtained. The final data collection was performed in July 2019. OS was defined as the time from the diagnosis of breast cancer to the date of death or the end of the study period.

Regarding the pathological assessment, surgical specimens were evaluated based on the following histopathologic features: tumor size, histological type of carcinoma, Black's nuclear grade (high, intermediate, low), modified Bloom-Richardson histological grade (high, intermediate, low), and estrogen receptor (ER), progesterone receptor (PR), and HER 2 expression status. ER and PR expression was assessed using the Allred score, which was calculated as the sum of the proportion and intensity scores for positivelystained tumor cells. Tumors with an Allred score of 3 or more were regarded as positive. An Immunohistochemical HER2 scores of $3+$ were considered positive. In cases of HER2 scores of 2+, HER2 gene amplification was confirmed using silver in situ hybridization. All specimens were reviewed by an experienced pathologist with 16 years of experience.

\section{CT protocol}

CT images used for sarcopenia analysis were derived from whole-body 18F-FDG PET/CT, which was performed in the supine position using a Discovery ST scanner (GE Healthcare, Milwaukee, USA). Non-enhanced CT scans were obtained from the base of the skull to the upper thigh (120 kV, 30-100 mA in AutomA mode; section width $=3.75 \mathrm{~mm}$ ) and had image quality similar to that of diagnostic CT.

Measurement of skeletal muscle, visceral fat, and subcutaneous fat amounts Body composition was evaluated using the acquired PET/CT images (Figure 2). An experienced radiologist (K.W.K) blinded to the clinical information performed the image analysis using the automated AsanJ-Morphometry ${ }^{\mathrm{TM}}$ software. AsanJ-Morphometry ${ }^{\mathrm{TM}}$ is a dedicated software for ImageJ (National Institutes of Health, Bethesda, USA) used to measure 


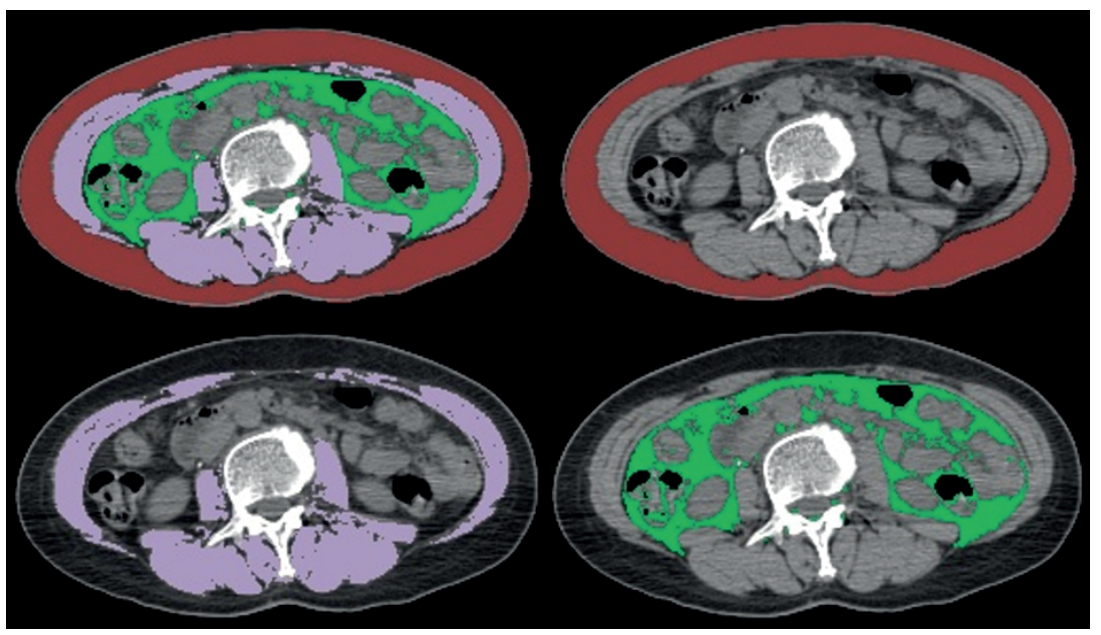

Figure 2. Body morphometric evaluation of abdominal fat and muscle areas. At the level of the inferior endplate of the L3 vertebra, the axial CT image is segmented into the total abdominal muscle area (purple), superficial fat area (brown), and visceral fat area (green).

$\mathrm{CT}=$ computed tomography.

the abdominal muscle and fat area. The AsanJ-Morphometry software is open to the public for research purposes and downloadable at http://datasharing.aim-aicro.com/morphometry. Anyone can access the software, text manual, and video manual at this website. The inferior endplate level of the L3 vertebra was selected as a landmark because it correlates with whole-body skeletal muscle mass and adipose tissue mass [11]. The total abdominal muscle area (TAMA), including all muscles on the selected axial images (i.e., psoas, paraspinal, transversus abdominis, rectus abdominis, quadratus lumborum, and internal and external obliques), was demarcated using predetermined thresholds ( -29 to +190 Hounsfield units). The visceral fat area (VFA) and subcutaneous fat area (SFA) were also demarcated using fat tissue thresholds (-190 to -30 Hounsfield units).

\section{Statistical analysis}

Regarding the clinicopathological information obtained and body morphometric analysis results, normality was assessed by inspecting frequency histograms or using the Kolmogorov-Smirnov test. Continuous data are presented as the means with standard deviations, and categorical data are presented as proportions.

All patients were divided into survival and non-survival groups, and clinicopathologic parameters were compared between the groups. Independent $t$-tests were used for analyzing continuous variables, and the $\chi^{2}$ test or Fisher's exact test was used for categorical variables.

Regarding body morphometric analysis, the means and standard deviations of the BMI, TAMA, SFA, and VFA among all patients were calculated. Patients were divided into 4 age groups: $<40$ years, $40-49$ years, $50-59$ years, and $\geq 60$ years. One-way analysis of variance and post hoc Tukey tests were used to compare the mean BMI, TAMA, SFA, and VFA among age groups.

To determine optimal cutoff values for body morphometric parameters with respect to predicting OS, receiver operating characteristic (ROC) curve analyses were performed using MedCalc software (version 10.3.0.0; MedCalc Software, Mariakerke, Belgium). The optimal cut-off values (in terms of sensitivity and specificity) for prediction of OS were those 
corresponding to the maximum Youden index [23]. To assess the independent contribution of each clinicopathologic variable to OS, univariate and multivariate Cox proportionalhazards regression analyses were performed and hazard ratios (HRs) with $95 \%$ confidence intervals (CIs) were calculated. Variables with a $p$-value $<0.1$ on univariate analysis were entered into the multivariate model. Subgroup analyses were performed based on breast cancer stage and patient age. All other statistical analyses were performed using the Statistical Package for the Social Sciences (SPSS) software (version 25.0; IBM Corp., Armonk, USA). A $p$-value $<0.05$ was considered statistically significant.

\section{RESULTS}

\section{Patients}

The clinical and pathologic characteristics of the patients are summarized in Table 1. The mean age was $48.9 \pm 10.2$ years. Ninety-three patients were aged $<40$ years, 242 were aged $40-49$ years, 158 were aged $50-59$ years, and 84 were aged $\geq 60$ years. In total, 114 patients underwent mastectomy, and 463 underwent breast-conserving surgery. The histological types of invasive breast cancer were as follows: invasive ductal carcinoma not otherwise specified $(\mathrm{n}=521,90.3 \%)$, invasive lobular carcinoma $(\mathrm{n}=19,3.3 \%)$, mucinous carcinoma $(\mathrm{n}=16$, $2.8 \%)$, invasive micropapillary carcinoma $(n=7,1.2 \%)$, metaplastic carcinoma $(n=4,0.7 \%)$, tubular carcinoma $(n=4,0.7 \%)$, invasive cribriform carcinoma $(n=2,0.3 \%)$, malignant phyllodes tumor $(n=2,0.3 \%)$, medullary carcinoma $(n=1,0.2 \%)$, and adenoid cystic carcinoma ( $\mathrm{n}=1,0.2 \%)$. The median follow-up period was 74 months (range: 7-90 months). In total, 49 of the 577 patients (8.5\%) died after a median of 45 months (range: 7-81 months).

\section{Body morphometric analysis results}

Mean values of the BMI, TAMA, SFA, and VFA by patient age are summarized in Table 2. The mean TAMA tended to decrease with increasing patient age. In contrast, the BMI, SFA, and VFA tended to increase with increasing patient age. One-way analysis of variance demonstrated that the mean values of BMI $(p<0.001)$, TAMA $(p<0.001)$, SFA $(p=0.015)$, and VFA $(p<0.001)$ differed significantly among age groups. Post hoc analyses revealed that the mean BMI was significantly lower in the $<40$ years age group compared to that in the $50-59$ years age group $(p=0.005)$ and $\geq 60$ years age group $(p<0.001)$. The BMI was also significantly lower in the $40-49$ years age group compared to that in the $\geq 60$ years age group $(p=0.013)$.

The mean TAMA was significantly decreased with increasing patient age, except between the $<40$ and $40-49$ years age groups $(p=0.826)$ (Figure 3$)$. The mean SFA was significantly lower in the $40-49$ years age group compared to that of the $\geq 60$ years age group $(p=0.048)$. The mean VFA was significantly decreased with increasing patient age, except between the $<40$ and $40-49$ years age groups $(p=0.335)$. Based on the Youden Index, the best TAMA threshold to predict OS was $83.7 \mathrm{~cm}^{2}$.

\section{Univariate and multivariate Cox proportional analysis}

Among the clinicopathologic parameters, larger tumor size (HR, 1.563; 95\% CI, 1.388-1.761; $p<0.001$ ), axillary lymph node metastasis (HR, 2.789; 95\% CI, 1.584-4.911; $p<0.001$ ), high histological grade (HR, 2.24; 95\% CI, 1.239-4.047; $p=0.008)$, high nuclear grade (HR, 3.318; 95\% CI, 1.714-6.425; $p<0.001$ ), receipt of neoadjuvant chemotherapy (HR, 2.918; 95\% CI, $1.662-5.124 ; p<0.001)$, and TAMA $\leq 83.7 \mathrm{~cm}^{2}$ (HR, 2.265; 95\% CI, 1.293-3.967; $\left.p=0.004\right)$ 
Table 1. Clinical and pathologic characteristics of patients

\begin{tabular}{|c|c|c|c|c|}
\hline Variable & Total $(n=577)$ & Survival group $(n=528)$ & Non-survival group $(n=49)$ & $p$-value \\
\hline Age $(y r)^{*}$ & $48.92 \pm 10.23$ & $48.73 \pm 9.98$ & $51 \pm 12.54$ & 0.223 \\
\hline Tumor size $(\mathrm{cm})^{*}$ & $2.14 \pm 1.42$ & $2.01 \pm 1.19$ & $3.62 \pm 2.62$ & $<0.001$ \\
\hline Axillary lymph node metastasis & & & & $<0.001$ \\
\hline Negative & $385(66.7)$ & $364(68.9)$ & $21(42.9)$ & \\
\hline Positive & $192(33.3)$ & $164(31.1)$ & $28(57.1)$ & \\
\hline Histologic grade & & & & 0.007 \\
\hline Low or intermediate & $337(58.4)$ & $318(60.2)$ & $19(38.8)$ & \\
\hline High & $214(37.1)$ & $188(35.6)$ & $26(53.1)$ & \\
\hline Unknown & $26(4.5)$ & $22(4.2)$ & $4(8.1)$ & \\
\hline Nuclear grade & & & & $<0.001$ \\
\hline Low or intermediate & $296(51.3)$ & $284(53.8)$ & $12(24.5)$ & \\
\hline High & $256(44.4)$ & $223(42.2)$ & $33(67.3)$ & \\
\hline Unknown & $25(4.3)$ & $21(4.0)$ & $4(8.2)$ & \\
\hline ER status & & & & 0.001 \\
\hline Negative & $152(26.3)$ & $129(24.4)$ & $23(46.9)$ & \\
\hline Positive & $423(73.3)$ & $397(75.2)$ & $26(53.1)$ & \\
\hline Unknown & $2(0.4)$ & $2(0.4)$ & $0(0)$ & \\
\hline PR status & & & & $<0.001$ \\
\hline Negative & $201(34.8)$ & $170(32.2)$ & $31(63.3)$ & \\
\hline Positive & $374(64.8)$ & $356(67.4)$ & $18(36.7)$ & \\
\hline Unknown & $2(0.4)$ & $2(0.4)$ & $0(0)$ & \\
\hline HER2 status & & & & 0.84 \\
\hline Negative & $470(81.5)$ & $431(81.6)$ & $39(79.6)$ & \\
\hline Positive & 101 (17.5) & $92(17.4)$ & 9 (18.4) & \\
\hline Unknown & $6(1.0)$ & $5(0.9)$ & $1(2.0)$ & \\
\hline Neoadjuvant chemotherapy & & & & $<0.001$ \\
\hline No & $446(77.3)$ & $419(79.3)$ & $27(55.1)$ & \\
\hline Yes & $130(22.5)$ & $108(20.5)$ & $22(44.9)$ & \\
\hline Unknown & $1(0.2)$ & $1(0.2)$ & $0(0)$ & \\
\hline Adjuvant chemotherapy & & & & 0.191 \\
\hline No & $243(42.1)$ & $218(41.3)$ & $25(51.0)$ & \\
\hline Yes & $333(57.7)$ & $309(58.5)$ & $24(49.0)$ & \\
\hline Unknown & $1(0.2)$ & $1(0.2)$ & $0(0)$ & \\
\hline Adjuvant radiation therapy & & & & 0.035 \\
\hline No & $111(19.2)$ & $96(18.2)$ & $15(30.6)$ & \\
\hline Yes & $465(80.6)$ & $431(81.6)$ & $34(69.4)$ & \\
\hline Unknown & $1(0.2)$ & $1(0.2)$ & $0(0)$ & \\
\hline BMI $\left(\mathrm{kg} / \mathrm{m}^{2}\right)^{*}$ & $23.86 \pm 3.7$ & $23.9 \pm 3.72$ & $23.46 \pm 3.52$ & 0.428 \\
\hline $\operatorname{TAMA}\left(\mathrm{cm}^{2}\right)^{*}$ & $90.67 \pm 13.81$ & $90.91 \pm 13.6$ & $88.08 \pm 15.86$ & 0.232 \\
\hline SFA $\left(\mathrm{cm}^{2}\right)^{*}$ & $164.19 \pm 62.52$ & $164.44 \pm 62.41$ & $161.49 \pm 64.25$ & 0.753 \\
\hline VFA $\left(\mathrm{cm}^{2}\right)^{*}$ & $85.33 \pm 49.02$ & $84.87 \pm 49.09$ & $90.24 \pm 48.44$ & 0.464 \\
\hline
\end{tabular}

$\mathrm{ER}=$ estrogen receptor; $\mathrm{PR}=$ progesterone receptor; HER2 = human epidermal growth factor receptor 2; $\mathrm{BMI}=$ body mass index; TAMA = total abdominal muscle area; SFA = subcutaneous fat area; VFA = visceral fat area.

*Data are means \pm standard deviations, unless otherwise noted, data are numbers of patients, with percentages in parentheses.

Table 2. BMI, TAMA, SFA, and VFA according to the patients' age

\begin{tabular}{|c|c|c|c|c|c|}
\hline Variables & $<40$ years old $(n=93)$ & $40-49$ years old $(n=242)$ & $50-59$ years old $(n=158)$ & $\geq 60$ years old $(n=84)$ & $p$-value \\
\hline BMI $\left(\mathrm{kg} / \mathrm{m}^{2}\right)$ & $22.72 \pm 3.59$ & $23.62 \pm 3.97$ & $24.29 \pm 3.35$ & $25.03 \pm 3.21$ & $<0.001$ \\
\hline TAMA $\left(\mathrm{cm}^{2} / \mathrm{m}^{2}\right)$ & $95.16 \pm 12.33$ & $93.8 \pm 12.64$ & $88.77 \pm 13.92$ & $80.26 \pm 12.54$ & $<0.001$ \\
\hline SFA $\left(\mathrm{cm}^{2}\right)$ & $155.55 \pm 71.17$ & $158.04 \pm 60.29$ & $171.12 \pm 62.27$ & $178.41 \pm 55.95$ & 0.015 \\
\hline VFA $\left(\mathrm{cm}^{2}\right)$ & $65.34 \pm 41.1$ & $74.7 \pm 41.36$ & $93.86 \pm 47.73$ & $122.06 \pm 56.98$ & $<0.001$ \\
\hline
\end{tabular}

Data are means \pm standard deviations.

$\mathrm{BMI}=$ body mass index; TAMA = total abdominal muscle area; SFA = subcutaneous fat area; VFA = visceral fat area.

were associated with worse OS (Table 3). ER positivity (HR, 0.387; 95\% CI, 0.221-0.678; $p<0.001$ ), PR positivity (HR, 0.296; 95\% CI, 0.166-0.53; $p<0.001$ ), and receipt of adjuvant radiation therapy (HR, $0.514 ; 95 \% \mathrm{CI}, 0.28-0.943 ; p=0.032)$ were associated with better OS. 


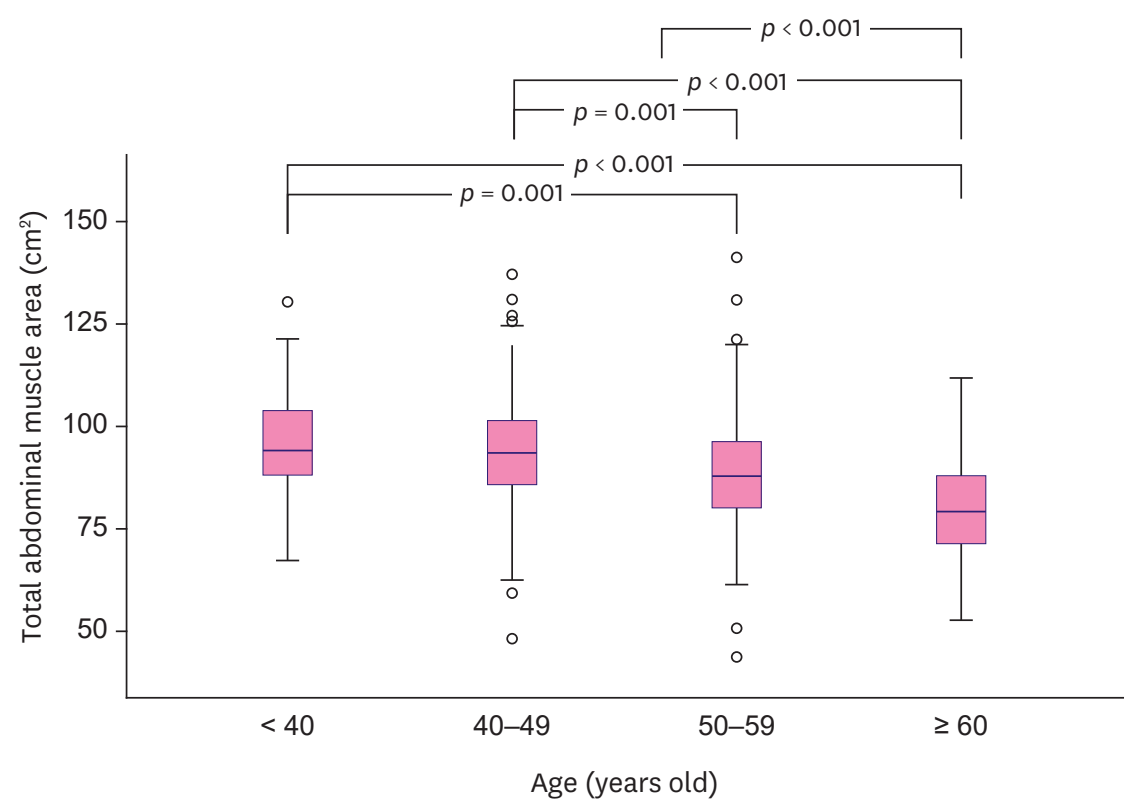

Figure 3. Boxplot graphs show a statistically significant difference in the TAMA among all age groups except between $<40$ and $40-49$ years age groups.

TAMA = total abdominal muscle area

Variables with a $p$-value $<0.1$ in the univariate analysis were entered into the multivariate Cox proportional-hazards model. The multivariate Cox analysis revealed that large tumor size (HR, 1.476; 95\% CI, 1.286-1.694; $p<0.001$ ), presence of axillary lymph node metastasis (HR, 2.608; 95\% CI, 1.343-5.065; $p=0.005$ ), high nuclear grade (HR, 2.355; 95\% CI, 1.124-4.932; $p=0.023)$, and TAMA $\leq 83.7 \mathrm{~cm}^{2}(\mathrm{HR}, 1.951 ; 95 \% \mathrm{CI}, 1.061-3.586 ; p=0.032)$ were associated with worse OS. ER positivity (HR, $0.381 ; 95 \% \mathrm{CI}, 0.195-0.744 ; p=0.005)$ and receipt of adjuvant radiation therapy (HR, $0.48 ; 95 \% \mathrm{CI}, 0.253-0.908 ; p=0.024)$ were associated with better OS. The Kaplan-Meier survival analysis showed that the OS times were significantly shorter in women with a lower TAMA value $\left(\leq 83.7 \mathrm{~cm}^{2}\right)$ than in those with a higher TAMA value $\left(>83.7 \mathrm{~cm}^{2}\right)(p=0.003$, log-rank test) (Figure 4A).

\section{Subgroup analysis in patients older than $\mathbf{5 0}$ years of age}

The univariate analysis revealed that tumor size (HR, 1.377; 95\% CI, 1.111-1.707; $p=0.004$ ), presence of axillary lymph node metastasis (HR, 3.039; 95\% CI, 1.365-6.766; $p=0.007$ ), nuclear grade (HR, 2.689; 95\% CI, 1.151-6.284; $p=0.022$ ), ER expression (HR, 0.294; 95\% CI, $0.132-$ 0.654; $p=0.003$ ), PR expression (HR, 0.134; 95\% CI, 0.046-0.391; $p<0.001$ ), neoadjuvant chemotherapy (HR, 2.312; 95\% CI, 1.022-5.233; $p=0.044)$, TAMA $\leq 77.14 \mathrm{~cm}^{2}$ (HR, 2.818; 95\% CI, 1.285-6.182; $p=0.01$ ), and SFA (HR, 0.399; 95\% CI, 0.176-0.903; $p=0.028)$ were associated with OS in patients $>50$ years of age.

The multivariate analysis results showed that tumor size (HR, 1.365; 95\% CI, 1.049-1.776; $p=0.02$ ), presence of axillary lymph node metastasis (HR, 2.559; 95\% CI, 1.009-6.492; $p=$ 0.048), PR expression (HR, 0.14; 95\% CI, 0.047-0.416; $p<0.001$ ), and TAMA $\leq 77.14 \mathrm{~cm}^{2}$ (HR, 2.856; 95\% CI, 1.218-6.695; $p=0.016$ ) remained as significant independent factors associated with OS in patients > 50 years of age (Table 4). The Kaplan-Meier survival analysis showed that the OS times were significantly shorter in women with a lower TAMA value $\left(\leq 77.14 \mathrm{~cm}^{2}\right)$ than in those with a higher TAMA value $\left(>77.14 \mathrm{~cm}^{2}\right)(p=0.007$, log-rank test) (Figure 4B). 
Table 3. Univariate and multivariate Cox proportional hazards analysis of variables associated with overall survival

\begin{tabular}{|c|c|c|c|c|}
\hline \multirow[t]{2}{*}{ Variable } & \multicolumn{2}{|l|}{ Univariate } & \multicolumn{2}{|c|}{ Multivariate } \\
\hline & $\mathrm{HR}(95 \% \mathrm{Cl})$ & $p$-value & $\mathrm{HR}(95 \% \mathrm{Cl})$ & $p$-value \\
\hline Patient age & $1.022(0.995-1.049)$ & 0.111 & & \\
\hline Tumor size & $1.563(1.388-1.761)$ & $<0.001$ & $1.476(1.286-1.694)$ & $<0.001$ \\
\hline Axillary lymph node metastasis & & $<0.001$ & & 0.005 \\
\hline Positive & $2.789(1.584-4.911)$ & & $2.608(1.343-5.065)$ & \\
\hline Negative & 1 & & 1 & \\
\hline Histologic grade & & 0.008 & & \\
\hline High & $2.24(1.239-4.047)$ & & & \\
\hline Low or intermediate & 1 & & & \\
\hline Nuclear grade & & $<0.001$ & & 0.023 \\
\hline High & $3.318(1.714-6.425)$ & & $2.355(1.124-4.932)$ & \\
\hline Low or intermediate & 1 & & 1 & \\
\hline ER status & & $<0.001$ & & 0.005 \\
\hline Positive & $0.387(0.221-0.678)$ & & $0.381(0.195-0.744)$ & \\
\hline Negative & 1 & & 1 & \\
\hline PR status & & $<0.001$ & & \\
\hline Positive & $0.296(0.166-0.53)$ & & & \\
\hline Negative & 1 & & & \\
\hline HER2 status & & 0.868 & & \\
\hline Positive & $1.063(0.515-2.2)$ & & & \\
\hline Negative & 1 & & & \\
\hline Adjuvant chemotherapy & & 0.196 & & \\
\hline Yes & $0.691(0.395-1.21)$ & & & \\
\hline No & 1 & & & \\
\hline Adjuvant radiation therapy & & 0.032 & & 0.024 \\
\hline Yes & $0.514(0.28-0.943)$ & & $0.48(0.253-0.908)$ & \\
\hline No & 1 & & 1 & \\
\hline Neoadjuvant chemotherapy & & $<0.001$ & & \\
\hline Yes & $2.918(1.662-5.124)$ & & & \\
\hline No & 1 & & & \\
\hline BMI $\left(\mathrm{kg} / \mathrm{m}^{2}\right)$ & & 0.177 & & \\
\hline $\mathrm{BMI}>23.01$ & $0.68(0.388-1.191)$ & & & \\
\hline $\mathrm{BMI} \leq 23.01$ & 1 & & & \\
\hline TAMA $\left(\mathrm{cm}^{2} / \mathrm{m}^{2}\right)$ & & 0.004 & & 0.032 \\
\hline TAMA $\leq 83.7$ & 2.265 (1.293-3.967) & & $1.951(1.061-3.586)$ & \\
\hline TAMA > 83.7 & 1 & & 1 & \\
\hline SFA $\left(\mathrm{cm}^{2}\right)$ & & 0.164 & & \\
\hline SFA $>134.39$ & $1.569(0.832-2.959)$ & & & \\
\hline SFA $\leq 134.39$ & 1 & & & \\
\hline VFA $\left(\mathrm{cm}^{2}\right)$ & & 0.057 & & \\
\hline VFA $>85.56$ & $1.725(0.984-3.023)$ & & & \\
\hline VFA $\leq 85.56$ & 1 & & & \\
\hline
\end{tabular}

$\mathrm{ER}$ = estrogen receptor; $\mathrm{PR}$ = progesterone receptor; HER2 = human epidermal growth factor receptor 2; $\mathrm{BMI}=$ body mass index; TAMA = total abdominal muscle area; SFA = subcutaneous fat area; VFA = visceral fat area.

\section{DISCUSSION}

Our study demonstrated that skeletal muscle depletion measured on CT was a strong prognostic biomarker $(\mathrm{HR}, 1.95)$, along with other well-known prognostic variables including a large tumor size, presence of axillary lymph node metastasis, high nuclear grade, absence of ER, and absence of adjuvant radiation therapy. In addition, the optimal TAMA threshold for predicting OS was $83.7 \mathrm{~cm}^{2}$ in all patients with non-metastatic breast cancer. Especially in postmenopausal patients older than 50 years of age, the best threshold was $77.14 \mathrm{~cm}^{2}$, and the hazard ratio was 2.86, which showed a greater effect of skeletal muscle depletion on the patients' OS. Most previous studies reporting the importance of skeletal muscle volume have 
A

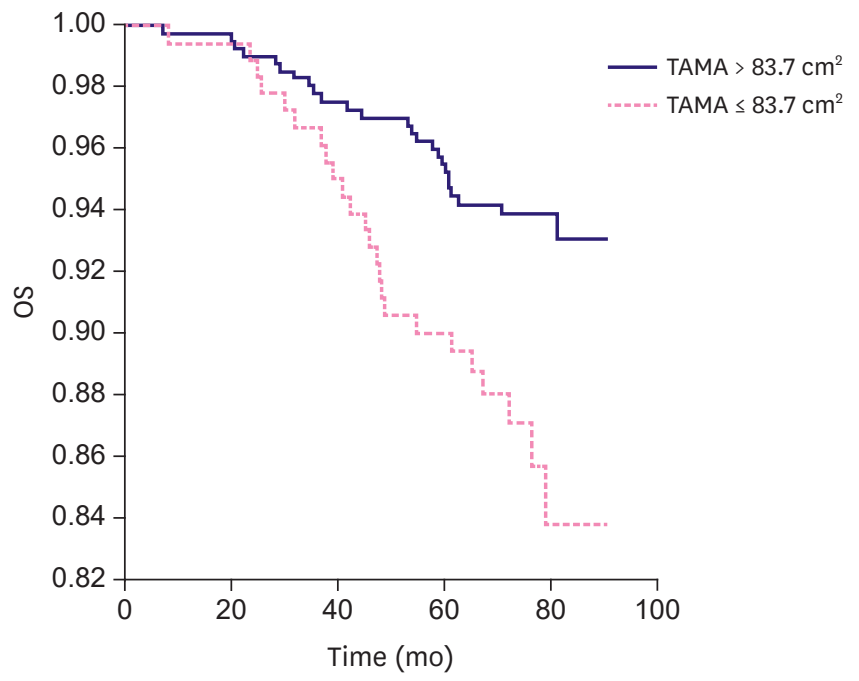

B

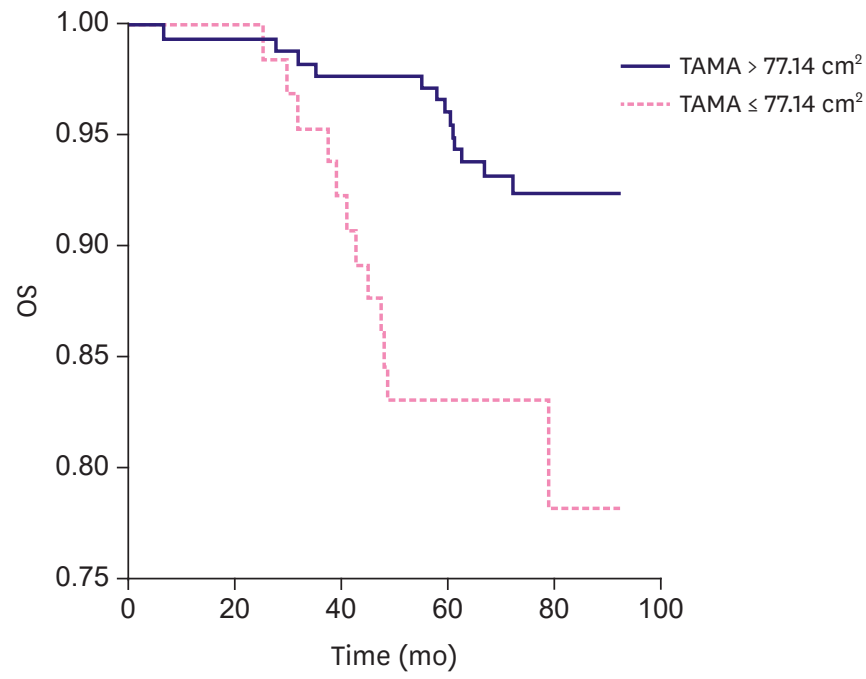

Figure 4. Kaplan-Meier curves show the OS according to TAMA in all 577 patients (A) and in patients older than 50 years of age (B). OS $=$ overall survival; TAMA $=$ total abdominal muscle area.

been performed in breast cancer patients from western countries, and our results could be useful for women in our country or other eastern countries.

Our study results are consistent with those of prior studies. Caan et al. [13] used data from 3,241 patients with non-metastatic breast cancer collected in the United States and demonstrated that patients with sarcopenia assessed by CT exhibited higher overall mortality (HR, 1.41; 95\% CI, 1.18-1.69) than patients without sarcopenia. In addition, Villaseñor et al. [12] showed that sarcopenia assessed on dual X-ray absorptiometry (DXA) was associated with an increased risk of overall mortality (HR, 2.86; 95\% CI, 1.67-4.89) in 471 survivors of non-metastatic (stage I-IIIA) breast cancer in the United States. Importantly, our study demonstrated that sarcopenia is also a prognostic factor in Asian patients.

In breast cancer patients, several prognostic factors have already been identified, which can be categorized into patient-, tumor-, and treatment-related factors. Commonly identified patient factors include age, obesity, ethnicity, and socioeconomic status [10]. Our study and other recent investigations provide evidence favoring the use of sarcopenia as a powerful prognostic factor. We used CT image for the quantification of skeletal muscle area, and the most important advantage of CT was that we could simultaneously obtain the skeletal muscle volume and subcutaneous and visceral fat masses. We analyzed the effect of BMI, subcutaneous fat volume, and visceral fat volume on patients' survival and interestingly, our results revealed that abdominal muscle mass was closely related to OS, while BMI and abdominal fat mass (i.e., VFA and SFA) were not; this challenges the general concept that obesity is a prognostic factor in breast cancer. In some studies, leaner people showed a higher risk of death than obese people, raising the issue of an "obesity paradox" [24,25]. Debate is currently ongoing regarding whether muscle or fat is more important in breast cancer; the findings of our study suggest that the former is more important.

Regarding the mechanism underlying the impact of sarcopenia on general health, the concept of muscle function has been revolutionary. In the past, skeletal muscle function was regarded as strictly limited to mobility and mechanical function. However, it is now known 
Table 4. Univariate and multivariate Cox proportional hazards analysis of variables associated with overall survival in patients older than 50 years

\begin{tabular}{|c|c|c|c|c|}
\hline \multirow[t]{2}{*}{ Variable } & \multicolumn{2}{|l|}{ Univariate } & \multicolumn{2}{|c|}{ Multivariate } \\
\hline & $\mathrm{HR}(95 \% \mathrm{Cl})$ & $p$-value & $\mathrm{HR}(95 \% \mathrm{Cl})$ & $p$-value \\
\hline Patient age & 1.039 (0.992-1.088) & 0.109 & & \\
\hline Tumor size & $1.377(1.111-1.707)$ & 0.004 & $1.365(1.049-1.776)$ & 0.02 \\
\hline Axillary lymph node metastasis & & 0.007 & & 0.048 \\
\hline Positive & $3.039(1.365-6.766)$ & & $2.559(1.009-6.492)$ & \\
\hline Negative & 1 & & & \\
\hline Histologic grade & & 0.061 & & \\
\hline High & $2.17(0.964-4.885)$ & & & \\
\hline Low or intermediate & 1 & & & \\
\hline Nuclear grade & & 0.022 & & \\
\hline High & $2.689(1.151-6.284)$ & & & \\
\hline Low or intermediate & 1 & & & \\
\hline ER status & & 0.003 & & \\
\hline Positive & $0.294(0.132-0.654)$ & & & \\
\hline Negative & 1 & & & \\
\hline PR status & & $<0.001$ & & $<0.001$ \\
\hline Positive & $0.134(0.046-0.391)$ & & $0.14(0.047-0.416)$ & \\
\hline Negative & 1 & & & \\
\hline HER2 status & & 0.384 & & \\
\hline Positive & $0.621(0.212-1.816)$ & & & \\
\hline Negative & 1 & & & \\
\hline Adjuvant chemotherapy & & 0.762 & & \\
\hline Yes & $1.132(0.508-2.519)$ & & & \\
\hline No & 1 & & & \\
\hline Adjuvant radiation therapy & & 0.088 & & \\
\hline Yes & $0.491(0.217-1.11)$ & & & \\
\hline No & 1 & & & \\
\hline Neoadjuvant chemotherapy & & 0.044 & & \\
\hline Yes & $2.312(1.022-5.233)$ & & & \\
\hline No & 1 & & & \\
\hline BMI $\left(\mathrm{kg} / \mathrm{m}^{2}\right)$ & & 0.25 & & \\
\hline $\mathrm{BMI}>23.6$ & $0.631(0.288-1.383)$ & & & \\
\hline $\mathrm{BMI} \leq 23.6$ & 1 & & & \\
\hline TAMA $\left(\mathrm{cm}^{2} / \mathrm{m}^{2}\right)$ & & 0.01 & & 0.016 \\
\hline TAMA $\leq 77.14$ & $2.818(1.285-6.182)$ & & $2.856(1.218-6.695)$ & \\
\hline TAMA > 77.14 & 1 & & 1 & \\
\hline SFA $\left(\mathrm{cm}^{2}\right)$ & & 0.028 & & \\
\hline SFA $>157.13$ & $0.399(0.176-0.903)$ & & & \\
\hline SFA $\leq 157.13$ & 1 & & & \\
\hline VFA $\left(\mathrm{cm}^{2}\right)$ & & 0.165 & & \\
\hline VFA $>87.41$ & $1.814(0.783-4.204)$ & & & \\
\hline VFA $\leq 87.41$ & 1 & & & \\
\hline
\end{tabular}

$\mathrm{ER}$ = estrogen receptor; $\mathrm{PR}$ = progesterone receptor; HER2 = human epidermal growth factor receptor 2; $\mathrm{BMI}=$ body mass index; TAMA = total abdominal muscle area; SFA = subcutaneous fat area; VFA = visceral fat area

that muscle has various other functions, including metabolic, endocrine, neurological, and psychological functions [26]. Notably, myokines (muscle-related cytokines) communicate with other organs to promote glucose production in the liver, lipolysis in adipose tissue, increased viability of pancreatic beta cells, and secretion of insulin [17,26]. In addition to these metabolic effects, a lack of muscle in sarcopenia can lead to physical disability, hospitalization, and poor quality of life [27,28]. These effects of muscle are closely related to disease resistance, treatment endurance (e.g., following major surgery and chemotherapy), and OS [17]. For example, women with breast cancer who had sarcopenia were much more likely to have severe chemotherapy-related side effects, hospitalizations, and treatment interruptions, all of which can influence OS [29]. 
In this context, the evaluation of sarcopenia is increasingly emphasized. Common methods for evaluating sarcopenia now include CT, DXA, and bioimpedance analysis. In breast cancer patients, CT scans are commonly acquired for staging and treatment planning. These clinically acquired CT scans are readily available for the majority of breast cancer patients; thus, they can be easily integrated into clinical practice without additional tests. Another advantage of CT is the simultaneous measurement of skeletal muscle volume and abdominal fat mass, including subcutaneous fat and visceral fat. Conversely, DXA and bioimpedance analysis are auxiliary procedures that involve additional time and cost. In our hospital, PET/ CT scans are performed in accordance with the institutional policy for all breast cancer patients who are scheduled to undergo surgery, and the quality of these scans is sufficient for assessment of disease severity, as well as for measurement of abdominal muscle and fat.

There were several limitations to this study. First, the study involved patients from a single center, which limits the generalizability of the findings. However, our hospital is a tertiary referral center and actively receives patients from many community centers in both rural and urban areas. Second, we included patients who underwent neoadjuvant chemotherapy, and we used the clinical stage and tumor size measured on initial MRI for these patients.

In conclusion, skeletal muscle depletion measured on CT scans is a strong prognostic biomarker for OS in patients with non-metastatic breast cancer. In patients older than 50 years of age, skeletal muscle depletion had a greater effect on patients' survival. The measurement of muscle mass on clinically acquired CT scans will help to guide management plans for the optimization of survival outcomes in patients with non-metastatic invasive breast cancer.

\section{REFERENCES}

1. Siegel RL, Miller KD, Jemal A. Cancer statistics, 2018. CA Cancer J Clin 2018;68:7-30. PUBMED | CROSSREF

2. Early Breast Cancer Trialists' Collaborative Group (EBCTCG), Peto R, Davies C, Godwin J, Gray R, Pan HC, et al. Comparisons between different polychemotherapy regimens for early breast cancer: metaanalyses of long-term outcome among 100,000 women in 123 randomised trials. Lancet 2012;379:432-44. PUBMED | CROSSREF

3. Early Breast Cancer Trialists' Collaborative Group (EBCTCG), Davies C, Godwin J, Gray R, Clarke M, Cutter D, et al. Relevance of breast cancer hormone receptors and other factors to the efficacy of adjuvant tamoxifen: patient-level meta-analysis of randomised trials. Lancet 2011;378:771-84. PUBMED | CROSSREF

4. O'Sullivan CC, Bradbury I, Campbell C, Spielmann M, Perez EA, Joensuu H, et al. Efficacy of Adjuvant trastuzumab for patients with human epidermal growth factor receptor 2-positive early breast cancer and tumors $\leq 2 \mathrm{~cm}$ : a meta-analysis of the randomized trastuzumab trials. J Clin Oncol 2015;33:2600-8. PUBMED | CROSSREF

5. DeSantis C, Ma J, Bryan L, Jemal A. Breast cancer statistics, 2013. CA Cancer J Clin 2014;64:52-62. PUBMED | CROSSREF

6. Adami HO, Malker B, Holmberg L, Persson I, Stone B. The relation between survival and age at diagnosis in breast cancer. N Engl J Med 1986;315:559-63. PUBMED | CROSSREF

7. Foulkes WD, Grainge MJ, Rakha EA, Green AR, Ellis IO. Tumor size is an unreliable predictor of prognosis in basal-like breast cancers and does not correlate closely with lymph node status. Breast Cancer Res Treat 2009;117:199-204. PUBMED | CROSSREF

8. Harvey JM, Clark GM, Osborne CK, Allred DC. Estrogen receptor status by immunohistochemistry is superior to the ligand-binding assay for predicting response to adjuvant endocrine therapy in breast cancer. J Clin Oncol 1999;17:1474-81.

PUBMED | CROSSREF 
9. Chia S, Norris B, Speers C, Cheang M, Gilks B, Gown AM, et al. Human epidermal growth factor receptor 2 overexpression as a prognostic factor in a large tissue microarray series of node-negative breast cancers. J Clin Oncol 2008;26:5697-704. PUBMED | CROSSREF

10. Ho-Huynh A, Tran A, Bray G, Abbot S, Elston T, Gunnarsson R, et al. Factors influencing breast cancer outcomes in Australia: a systematic review. Eur J Cancer Care (Engl) 2019;28:e13038. PUBMED | CROSSREF

11. Lee K, Shin Y, Huh J, Sung YS, Lee IS, Yoon KH, et al. Recent issues on body composition imaging for sarcopenia evaluation. Korean J Radiol 2019;20:205-17. PUBMED | CROSSREF

12. Villaseñor A, Ballard-Barbash R, Baumgartner K, Baumgartner R, Bernstein L, McTiernan A, et al. Prevalence and prognostic effect of sarcopenia in breast cancer survivors: the HEAL study. J Cancer Surviv 2012;6:398-406. PUBMED | CROSSREF

13. Caan BJ, Cespedes Feliciano EM, Prado CM, Alexeeff S, Kroenke CH, Bradshaw P, et al. Association of muscle and adiposity measured by computed tomography with survival in patients with nonmetastatic breast cancer. JAMA Oncol 2018;4:798-804. PUBMED | CROSSREF

14. Song EJ, Lee CW, Jung SY, Kim BN, Lee KS, Lee S, et al. Prognostic impact of skeletal muscle volume derived from cross-sectional computed tomography images in breast cancer. Breast Cancer Res Treat 2018;172:425-36. PUBMED | CROSSREF

15. Weinberg MS, Shachar SS, Muss HB, Deal AM, Popuri K, Yu H, et al. Beyond sarcopenia: characterization and integration of skeletal muscle quantity and radiodensity in a curable breast cancer population. Breast J 2018;24:278-84. PUBMED | CROSSREF

16. Shachar SS, Deal AM, Weinberg M, Nyrop KA, Williams GR, Nishijima TF, et al. Skeletal muscle measures as predictors of toxicity, hospitalization, and survival in patients with metastatic breast cancer receiving taxane-based chemotherapy. Clin Cancer Res 2017;23:658-65. PUBMED | CROSSREF

17. Aleixo GF, Williams GR, Nyrop KA, Muss HB, Shachar SS. Muscle composition and outcomes in patients with breast cancer: meta-analysis and systematic review. Breast Cancer Res Treat 2019;177:569-79. PUBMED | CROSSREF

18. Yang M, Shen Y, Tan L, Li W. Prognostic value of sarcopenia in lung cancer: a systematic review and metaanalysis. Chest 2019;156:101-11. PUBMED | CROSSREF

19. Kamarajah SK, Bundred J, Tan BH. Body composition assessment and sarcopenia in patients with gastric cancer: a systematic review and meta-analysis. Gastric Cancer 2019;22:10-22. PUBMED | CROSSREF

20. Mintziras I, Miligkos M, Wächter S, Manoharan J, Maurer E, Bartsch DK. Sarcopenia and sarcopenic obesity are significantly associated with poorer overall survival in patients with pancreatic cancer: systematic review and meta-analysis. Int J Surg 2018;59:19-26. PUBMED | CROSSREF

21. Nakamura N, Hara T, Shibata Y, Matsumoto T, Nakamura H, Ninomiya S, et al. Sarcopenia is an independent prognostic factor in male patients with diffuse large B-cell lymphoma. Ann Hematol 2015;94:2043-53. PUBMED | CROSSREF

22. Moons KG, Altman DG, Reitsma JB, Ioannidis JP, Macaskill P, Steyerberg EW, et al. Transparent Reporting of a multivariable prediction model for Individual Prognosis or Diagnosis (TRIPOD): explanation and elaboration. Ann Intern Med 2015;162:W1-73. PUBMED | CROSSREF

23. Youden WJ. Index for rating diagnostic tests. Cancer 1950;3:32-5. PUBMED | CROSSREF

24. Gonzalez MC, Pastore CA, Orlandi SP, Heymsfield SB. Obesity paradox in cancer: new insights provided by body composition. Am J Clin Nutr 2014;99:999-1005. PUBMED | CROSSREF

25. Lennon H, Sperrin M, Badrick E, Renehan AG. The obesity paradox in cancer: a review. Curr Oncol Rep 2016;18:56. PUBMED | CROSSREF 
26. Kaji H. Effects of myokines on bone. Bonekey Rep 2016;5:826. PUBMED | CROSSREF

27. Beaudart $\mathrm{C}$, Zaaria M, Pasleau F, Reginster JY, Bruyère O. Health outcomes of sarcopenia: a systematic review and meta-analysis. PLoS One 2017;12:e0169548. PUBMED | CROSSREF

28. Bazzocchi A, Diano D, Ponti F, Salizzoni E, Albisinni U, Marchesini G, et al. A 360-degree overview of body composition in healthy people: relationships among anthropometry, ultrasonography, and dualenergy x-ray absorptiometry. Nutrition 2014;30:696-701.

PUBMED | CROSSREF

29. Prado CM, Baracos VE, McCargar LJ, Reiman T, Mourtzakis M, Tonkin K, et al. Sarcopenia as a determinant of chemotherapy toxicity and time to tumor progression in metastatic breast cancer patients receiving capecitabine treatment. Clin Cancer Res 2009;15:2920-6.

PUBMED | CROSSREF 